\title{
The Innovative Structural Measures about the Temperature Late-poured Band and Construction Joints in the Underground Structure of Tall Building
}

\author{
Fang $\mathrm{TaO}^{1, \mathrm{a}}$ and Fang Guangxiu ${ }^{1, \mathrm{~b}}$ \\ ${ }^{1}$ Department of Civil Engineering,College of Engineering, Yanbian University, Yanji, 133002, China \\ a2923212871@qq.com, b1798602756@qq.com
}

Keywords: The late-poured band of basement, The construction joints, The steel water-stop strip, The structural measures.

\begin{abstract}
With the development of tall building, the requirements for the structural design and construction of building becomes higher and higher, especially the design of the late-poured band in underground structure and the construction measures in the projects. In this paper, taking a high-rise frame structure engineering as an example in Yanji Jilin, combines with the theoretical knowledge and experience of construction, it analyses the problems during the design and construction of the late-poured band in basement, and finally proposes the innovative structural measures about the temperature late-poured band and construction joints in the underground structure of high-rise building. Testified by the practice, the construction quality meets the requirements of specification acceptance standard, so this approach can be applied to similar project.
\end{abstract}

\section{Introduction}

The main purpose to set the late-poured band is solving the problem about the temperature expansion and structure settlement caused by the complex structure of buildings, so we can divide into it for the temperature late-poured band, the expansion late-poured band and the settlement late-poured band according to the following function [1-3]. But in its design, except ensure the necessary gap, we should also pay attention to adjust the plane size and the structure layout to avoid the collision damage [4]; about the construction of the late-poured band, when the age of both sides concrete is after 42 days later, we usually use the concrete to fill in the location of the band, and the construction of the late-poured band must be used the special technical measures [5] to deal with. But in the actual construction process, we will meet some problems for example a complex die, the not ideal concrete surface and so on, they even influences the structure quality and the normal use of buildings [6]. In this paper, the temperature late-poured band as an example, we put forward the innovative structural measures about the temperature late poured band and construction joints in the underground structure of high-rise building. The construction quality meets the requirements of specification acceptance standard, so this approach can be applied to similar project.

\section{The Engineering Situation}

This project is a high-rise frame structure building, a hotel in Yanji City, Jilin Province, and its construction area is $43112.21 \mathrm{~m}^{2}$. The basement is a layer of underground garage, the construction area is $6991.51 \mathrm{~m}^{2}$. This project uses the independent foundation for the reinforced concrete column, the supporting course is the politic siltstone, and the characteristic value of subgrade bearing capacity is $550 \mathrm{KPa}$, so the design class of foundation is $\mathrm{B}$. The concretes of foundation, exterior wall and basement floor are all used P6 impervious concrete, and the concrete strength grade is C40. The concrete of basement floor, partitions and exterior walls should be poured to above the bottom board $300 \mathrm{~mm}$ with a whole pouring. At the same time, the concrete between constructions joints should be poured completely, no any construction joints are left in the walls (except the construction late-poured band). 


\section{The Calculation of the Late-Poured Belt in the Basement Floor}

On the shrinkage of concrete, the calculation models of the shrinkage of concrete have the CEB-FIP [7], ACI209 [8], B3 [9] and so on. This project is combined with the "The Construction Standard of Large Volume Concrete" (GB50496-2009) in Appendix B, sets up the late-poured band. The late-poured band is set to the north and south direction, and the length is $70400 \mathrm{~mm}$, the width is $800 \mathrm{~mm}$.

\section{The Innovative Structural Measures about the Temperature Late-poured Band and Construction Joints}

The Innovative Structural Measures about the Temperature Late-poured Band in the Soleplate of the Basement. The thickness of basement floor is $550 \mathrm{~mm}$, the thickness of concrete about protective layer on the top is $20 \mathrm{~mm}$, and beneath is $40 \mathrm{~mm}$; the whole plate be designed two-layer and two-side reinforcements C12@300, the local additional and the full-length reinforcement is distributed in interval; the cushion makes by $\mathrm{C} 15$ plain concrete, $100 \mathrm{~mm}$ thick; if the elevation of base exceed the design (or ultra deep), we must increase the thickness of cushion and it also can be deal with the slope by 60 degrees. According to the existing project, we make the decision with the construction units and the on-site supervision engineers, design the innovative structural measures about the temperature late-poured band in the soleplate of the basement and it would be shown in Fig. 1.

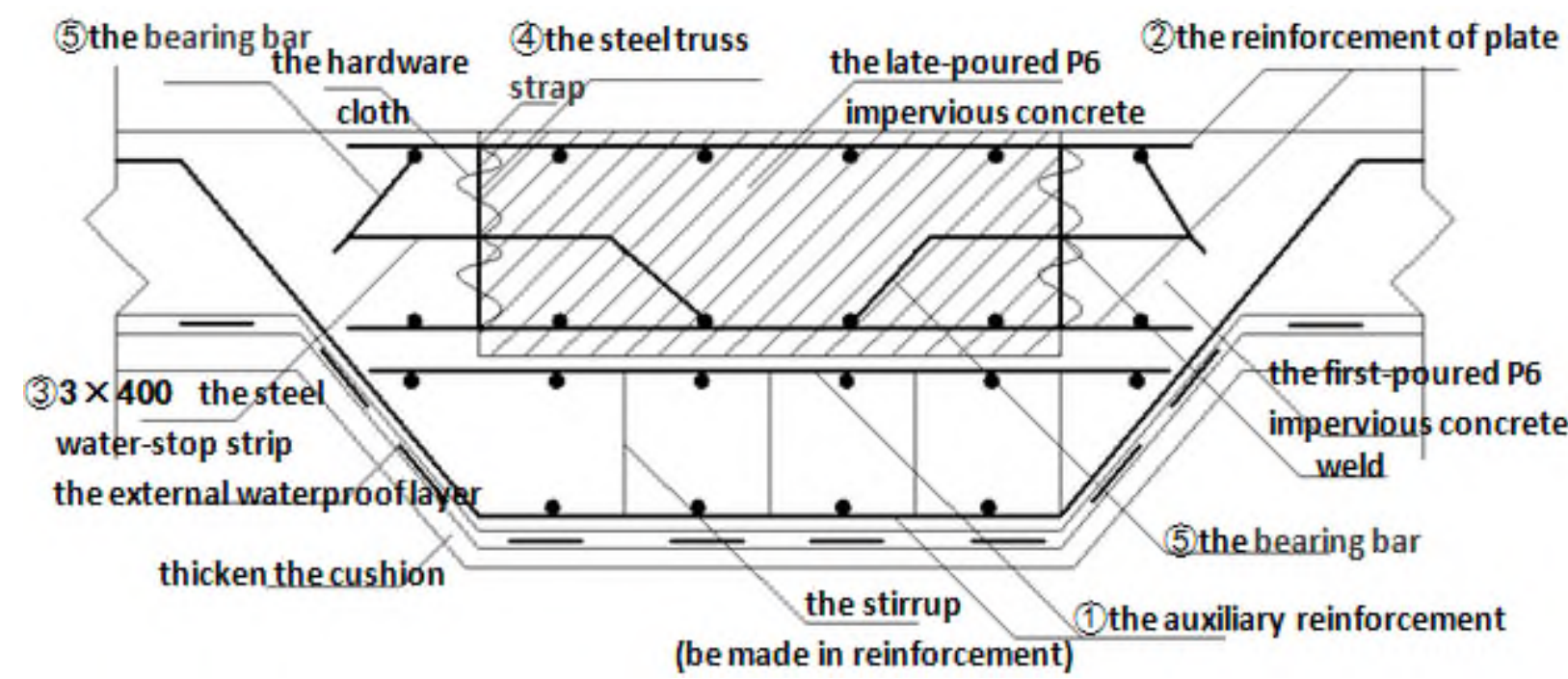

Fig. 1 The sketch map of innovative structural measures about the temperature late-poured band in the soleplate of the basement.

The specific construction processes as follows: after the cushion completed and reached the specified strength $\mathrm{C} 15$, first we paste the external waterproof layer (the CLF waterproofing membrane, $1.5 \mathrm{~mm}$ double), then lay the auxiliary reinforcement $\mathrm{C} 12 @ 300$, and add the stirrups (Fig. 2) to the middle part of the auxiliary reinforcement, the vertical and horizontal space is $1 \mathrm{~m}$, we prevent the movement of the stirrups by using the reinforced thread; second we lay the plate reinforcement. In both sides of the construction joints we first lay the $3 \times 400$ steel water-stop strip, meanwhile weld the steel truss in the upper and the lower side of the steel (the steel truss is made by welding the A8 reinforced frame and wrapped with twice hardware cloths, the structure shows in Fig. 3), we also make the plate reinforcement just go through the steel truss, finally use the wire banding the steel truss and the plate reinforcement together (to prevent the both sides of steel truss occurring the displacement). In case of the special situation, the soleplate do not set the construction joints consist of the late-poured band according to the original plan, we will install the inflated water-stop rubber when the second pouring concrete. 


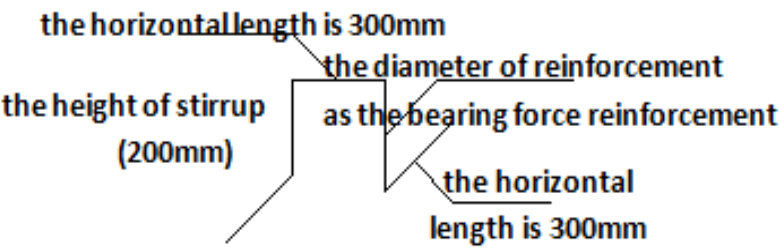

Fig. 2 The sketch map of stirrups.

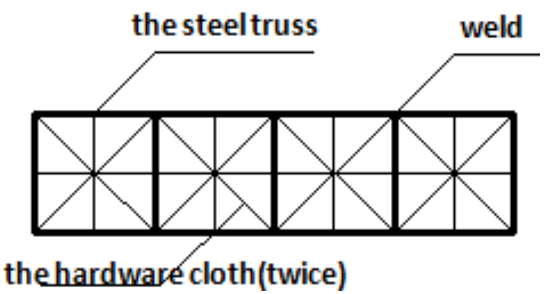

Fig. 3 The sketch map of steel truss.

The reasons of using the hardware cloths are that: the low market prices and the advantage of the size, the cloth can not only prevent the concrete flowing into construction joints while pouring concrete, also can obtain the joint surface well so that we can combine the before and after concrete simply. At the same time, in order to prevent occurring the displacement in the process of pouring concrete with the steel water-stop strip, we weld the bearing bar A10 with the steel water-stop strip and the plate reinforcement.

The Innovative Structural Measures about the Temperature Late-poured Band and Construction Joints in the Exterior Wall of Basement.

The Innovative Structural Measures about the Temperature Late-poured Band and Construction Joints in the Shear Wall. In the shear wall with setting the late-poured band, in order to preventing the debris falling into the late-poured belt so that affecting the quality of the project, we make it closed by means of using the brick masonry retaining wall outside and the wooden template inside. The design of the late-poured band in the shear wall and the innovative structural measures about the construction joint will be shown in Fig. 4.

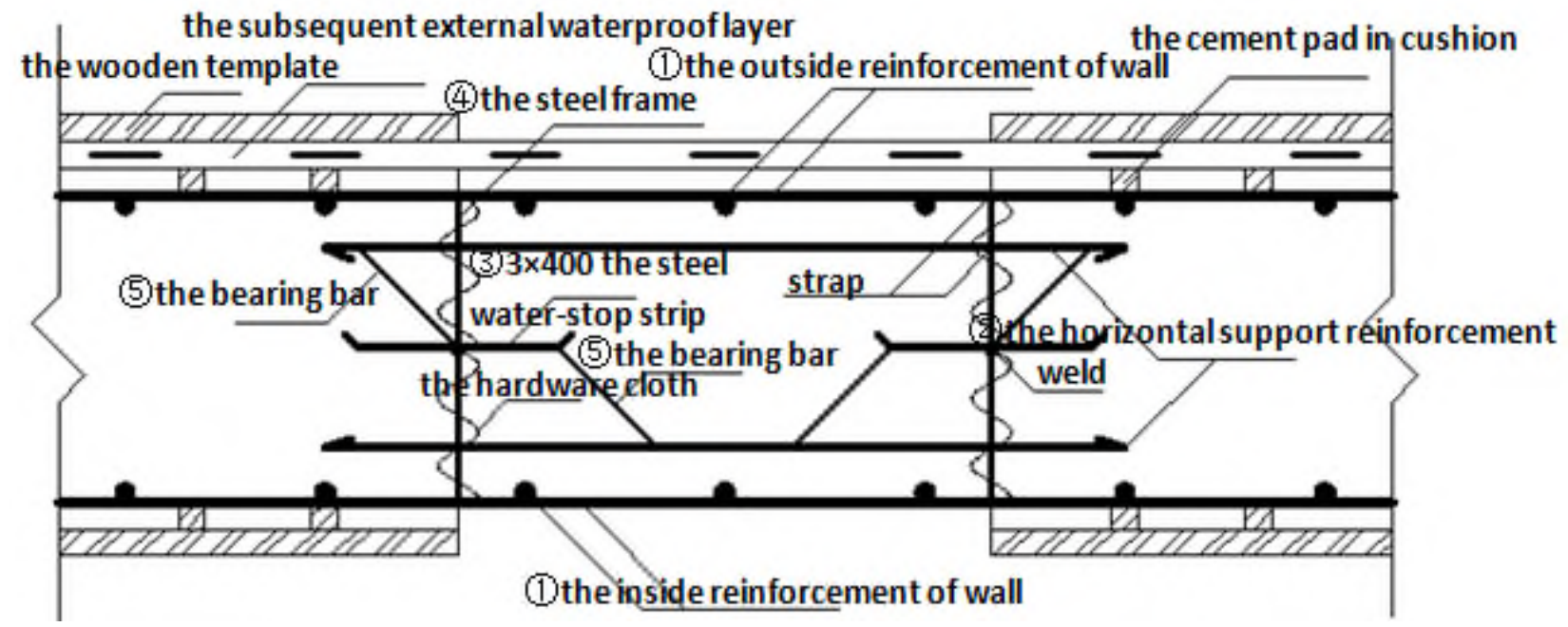

Fig. 4 The sketch map of innovative structural measures about the temperature late-poured band in the shear wall.

The construction processes: first, we weld the steel water-stop strip of the late-poured band in the shear wall and the installed steel water-stop strip of the late-poured band in the plate by the vertical way, and then weld the steel truss to the both sides of the steel water-stop strip; second install the horizontal support reinforcement C10@300 and the wall reinforcement C12@300, at this time, use scissors cut the hardware cloth into small holes so that ensure the horizontal support reinforcement can through the steel truss, and use the wire banding the steel truss and the reinforcement together; finally, we weld the bearing bar A10 with the steel water-stop band and the horizontal support reinforcement, after stripping later, paste the external waterproof layer in the outside of the wall (the CLF waterproofing membrane). Among them, using the wire avoids the quality problems by bringing for the welding, at the same time, the welding also makes the reinforcements form a whole, effectively ensure the stress. Also it prevents the steel truss occurring the displacement because of the lateral pressure. 
The Innovative Structural Measures about the Horizontal Construction Joints in the Exterior Wall of Basement. The innovative structural measures about the horizontal construction joints in the exterior wall of basement are shown in Fig. 5. First of all, we bind the wall reinforcement C12@300, then make from the design of horizontal construction joints in the $300 \mathrm{~mm}$ height of basement, and put the water-stop steel in the location of the figure, while taking a short steel A8, weld it with the wall reinforcement and the water-stop steel and it will be located the water-stop steel well. We set the stirrup in the $50 \mathrm{~mm}$ height position of the water-stop steel with banding the wall reinforcement. When the second pouring concrete, the surface of construction joints must be chiseled, rinsed, moist, [10] and we will use the $10-15 \mathrm{~mm}$ pure cement mortar layer so that ensure combining the before and after concrete simply. Welding the short steel can prevent occurring the displacement in the process of pouring concrete with the water-stop steel to ensure the sealing effect; and the purpose of setting the stirrups is guaranteed the wall pass force uniform, not from the effect of construction joints.

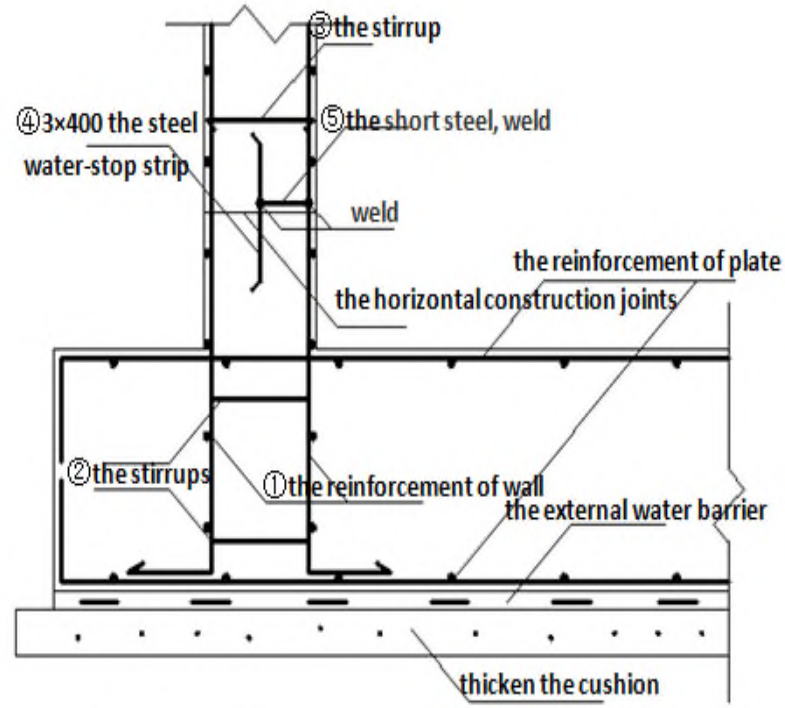

Fig. 5 The sketch map of innovative structural measures about the horizontal construction joints in the exterior wall of basement.

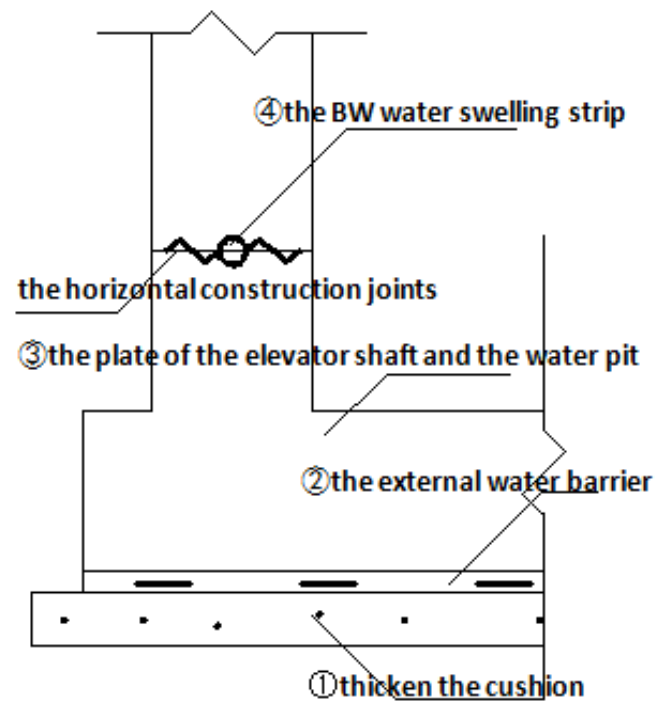

Fig. 6 The sketch map of innovative structural measures about the horizontal construction joints in the plate of elevator shaft and water pit.

The Innovative Structural Measures about the Horizontal Construction Joints in the Plate of Elevator Shaft and Water Pit. In the horizontal construction joints, we set the water swelling strip by embedding the hard wood to seal for positioning [11]. First the concrete hardened, we exclude the hard wood to form a groove, second, fix the sealing strip in the groove, and then use the WJ interface adhesive which have the significant ability to bond to old concrete interface, bond the sealing strip in paste form, last move the cement nails into the way to reinforce. At the same time, the height of revealing to meet the water surface about the water swelling strip should be less than $150 \mathrm{~mm}$. Considered in before pouring the second concrete, the sealing strip which in outside occurred the prior expansion because of the water, so in the project we use the BW water swelling strip. The specific application is shown in Fig. 6.

\section{The Construction Verification}

The engineering quality in this unit project of a hotel about the high-rise frame structure building of the basement is good from the inspection of the design unit and the supervision unit, especially the part of late-poured belt. After the inspection, the deformation conforms to the standard requirements; the construction quality is less than the quality assessment requirements of the standard [12]; the water-stop constructions are in line with the 5.7.5 requirements of GB 50208 - 2002 " Code for Acceptance of Construction Quality of Underground Waterproof ". 


\section{Conclusion}

In this paper, it combines with the engineering project and proposes the innovative structural measures about the temperature late poured band and construction joints in the underground structure of high-rise building as follow:

(1) Let the steel truss which is around with the hardware cloth weld in the upper and lower part of the water-stop steel to form a whole places in both sides of the post pouring belt, then use the wire band the plate reinforcement which pass through the steel truss, at the same time, weld the support reinforcement with the water-stop belt.

(2) For the horizontal construction joints of underground wall, we position the water-stop steel by welding the short rib. At the same time, in order to ensure the wall stress evenly, we bind the stirrups without construction joints affect.

The innovative construction measures proposed in this paper not only solve the problems of the traditional construction measures, but also meet the requirements of specification acceptance standard. So this approach can be applied to similar project.

\section{References}

[1] H. M. Su, Y. X. Zhang, L. Q. Feng, Y. F. Du and F. B. Zhang, Numerical Simulation on the Post-cast Strips Superior Water Stop Technology in the Multi-tower High-rise Structure with Enlarged Base. Constr. Technol. 8 (2014) 108-117.

[2] Q. F. Zhao And S. Zeng, Application of super-length concrete structure late poured band construction technique. Archit. Technol. 2 (2011) 120-123.

[3] L. Y. Chen, J. Zhang and B. C. Wang, Construction technique of pre-embedded grouting pwe for post-pouring belt in waterfront super-deep foundation. Archit. Technol. 11 (2012) 974-976.

[4] F. Ge, Problems in the Design and Construction of the Post-pouring Belt. China Sci. Technol. Rev. 2012 (21).

[5] Y. Shi, Discussions on the Design of the Post-pouring Belt in Concrete Structure Design. ChengShi Jianshe LiLun Yan Jiu, 2013 (26).

[6] L. S. Meng and G. X. Fang, Research on Structural Measures for the Post-pouring Zone of Basement and Construction Joint of the Wall in High-rise Building, J. Yanbian U. (Nat. Sci.), 6 (2014) 158-162.

[7] A. Ghali, R. Favre and M. Elbadry. Concrete structure: stress and strain. Spon Press, London, Thirdedition, 2002.

[8] ACI Committee 209 (1992). Prediction of Creep, Shrinkage and Temperature Effects in Concrete Structures, Manual of Concrete Practice, Part 1. American Concrete Institute, 209R1-92.

[9] Z. P. Bazant and S. Baweja, Creep and Shrinkage Prediction Model for Analysis and Design of Concrete Structures Model B3, RILEM Recommendation. Mater. Struct. 28 (1995) 357-365.

[10] W. C. Jin, The Several Structural Measures about the Construction of the Post-pouring Belt. Architect. Technol. 2003 (37) 493-494.

[11]L. X. Zhou, Y. Z. Wang and Q. C. Wang, Design and Construction of Waterproof in Kunlun Railway Tunnel. J. Lanzhou Railway U. (Nat. Sci.), 12 (2002) 82-86.

[12] Ministry of Housing and Urban-Rural Construction of the People's Republic of China. GB50010-2010《Code for Design of Concrete Structures》. Beijing: China Building Industry Press, 2011. 